\title{
Sardar Sarovar Dam: A Case Study of Development-induced Environmental Displacement
}

\author{
Laurie Uytterlinde Flood
}

\begin{abstract}
This article discusses how the Sardar Sarovar dam in India is a case of a development project which causes environmental displacement on a massive scale. This occurs through evictions and indirectly through the impairment of livelihoods by environmental changes. The problems of resettlement and rehabilitation are emphasized in the article as are further displacement effects due to this process. The inequality between development beneficiaries and those who must bear the majority of the development costs is also addressed.
\end{abstract}

\section{Précis}

Cet article avance une argumentation selon laquelle le barrage du Sardar Sarovar en Inde est clairement un cas de projet de développement entraînant des déplacements de populations pour raisons environnementales sur une base massive. Le phénomène se manifeste sous la forme d'évictions et indirectement sous la forme d'une détérioration des conditions de vie due aux changements environnementaux. Le problème de la relocalisation des populations et de leur réhabilitation au milieu est mis en reliefdans le présent article, ainsi qu'un certain nombre d'autres effets dus à ce processus de déplacement de populations. Les inégalités entre les bénéficiaires de ces projets de développement et ceux qui doivent assumer le gros des coûts $d u$ développement est aussi abordé.

The Sardar Sarovar Dam is a case of a development project which is both directly and indirectly causing environmental displacement on a massive scale. Moreover, this project is also set-

Laurie Uytterlinde Flood is Graduate Student, Faculty of Environmental Studies, York University, Toronto. ting the stage for further incidents of environmental displacement in the future through a combination of less than adequate resettlement and rehabilitation of displaced persons and a general lack of attention to potential environmental impacts of the project. As well, this project creates inequality between development beneficiaries and those who must bear the majority of the development costs.

\section{Historical Overview}

The Narmada River is India's fifth longest river, starting in the central Indian state of Madhya Pradesh and flowing west through the states of Maharashtra and Gujarat to the Gulf of Khambhat (see map). The Sardar Sarovar Dam is only one of a proposed thirty large dams-ten to be built on the Narmada itself, and the rest on its tributaries. In addition to these $30 \mathrm{ma}-$ jor dams, the Narmada Valley Project also envisions 135 medium and 3,000 minor dams (Baviskar 1995, 199). Proposals for damming the Narmada have been around for many decades but were delayed until the mid-eighties because of political wrangling over the sharing of the costs and benefits among the three states (ibid., 199). The dream of political leaders and planning officials within Gujarat for many years, the Sardar Sarovar Dam Project finally commenced in 1987 (Morse and Berger 1992, 5).

Dam building is integral to India's development vision, which until recently was modelled on the Sovietstyle centralized, state-led economic development with an emphasis on industrialization (Hardgrave and Kochanek 1993, 354-55). Within this context, dams are ideal since they are amenable to top-down planning, provide tangible benefits to industrialization needs vis-à-vis hydroelectricity, and also to modernized agriculture in terms of irrigation (Savur 1995, 156). Indeed, Prime Minister Jawaharlal Nehru represented dams as India's "secular temples" (Morse and Berger 1992, 3).

The Sardar Sarovar Dam is the second largest project in the Narmada Valley in terms of both total area submerged and the numbers of people displaced (Baviskar 1995, 199). According to the independent review conducted by Bradford Morse and Thomas Berger for the World Bank, once completed the Sardar Sarovar Dam Project will submerge approximately 37,000 hectares of land for the reservoir, and approximately 80,000 hectares for the extensive canal works. It will displace at least 100,000 people who reside in approximately 245 villages. Approximately 140,000 additional farmers will be affected by the canal and irrigation system, and an unknown number of people, ranging somewhere in the thousands, will be affected by the disturbance of downstream fisheries (Morse and Berger 1992, xii-xiii).

\section{Justifications for the Project}

Sardar Sarovar is a classic example of a development project which is deemed to be "in the national interest." The justification given for this dam project is that it will bring enormous benefits to millions, whilst displacing relatively few people (ibid.,5). It will bring drinking water to about 40 million people living in the drought-prone regions of Gujarat. As well, it will provide irrigation to a vast area within Gujarat and 2 districts in Rajasthan, increasing the expected net value of their area's agricultural production sixfold (Morse and Berger 1992, xii, 5; Wood 1993, 974). In addition, the Sardar Sarovar Project will provide much needed hydroelectric power. These justifications are couched in the utilitarian terms of 
The Sardar Sarovar Projects Area

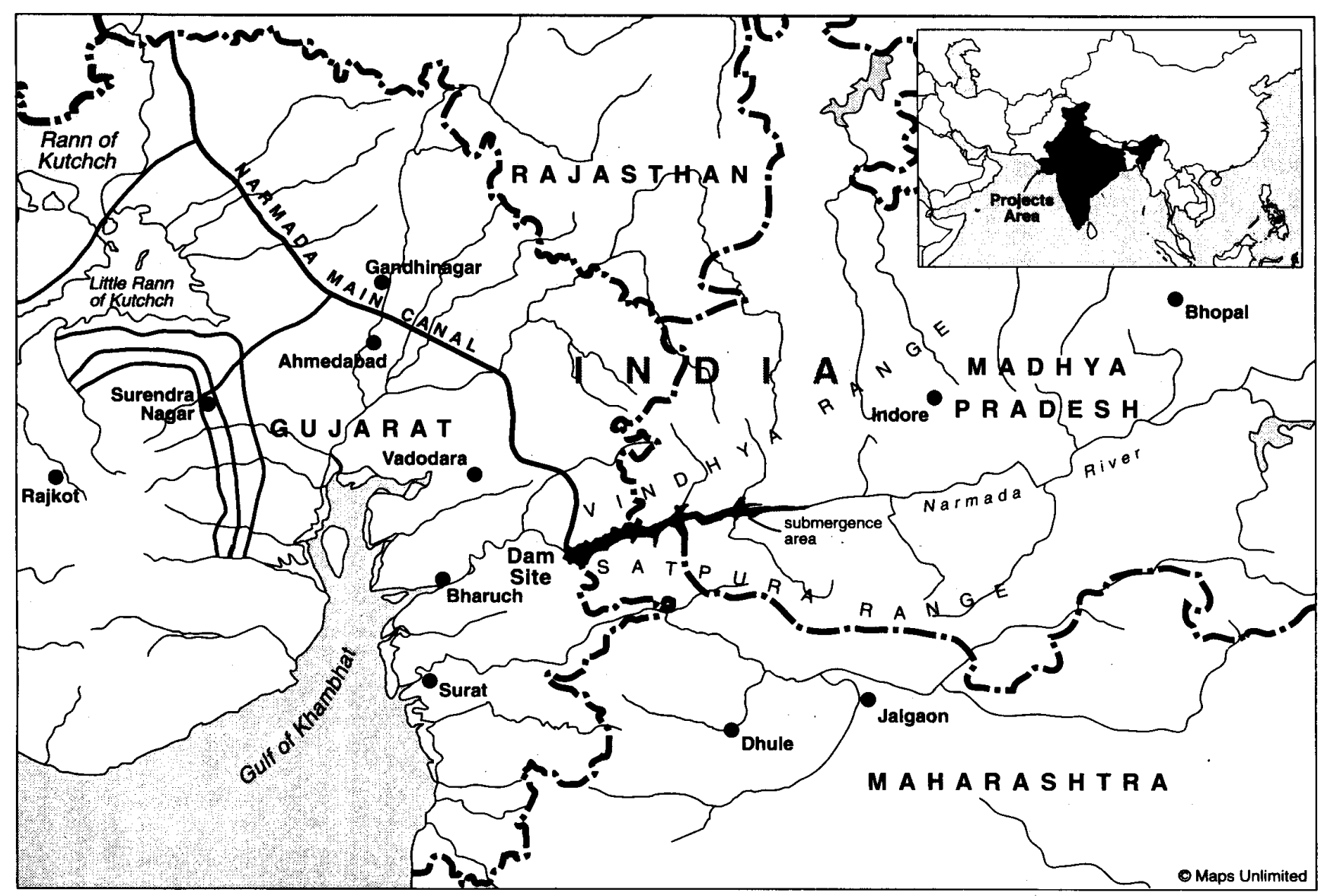

Source: Bradford Morse and Thomas Berger, Sardar Sarovar: Report of the Independent Review (Ottawa: Resource Future International, 1992), xxvi.

balancing the needs of the many against those of a few.

Moreover, even the discomfort of the few is seen to be minimal according to many project proponents. The majority of people to be displaced by this project "are tribal people whose lands are said to consist of steep, rocky ground and degraded forests" (Morse and Berger 1992, 5). Thus, proponents say, not only is the land to be lost of marginal value, but this project can actually be seen as a development opportunity for displaced people since there is a resettlement component to the project ${ }^{1}$ (ibid., 1992, 5-6).

It is possible that development-induced environmental displacement could be justified in certain cases where the people to be displaced were properly consulted beforehand, and then sufficiently compensated in ways acceptable to them. Michael Cernea proposes this justification in response to these ethical problems of displacement. Cernea argues that incidents of development-induced displacement are morally justified so long as the displaced persons are left no worse off than they were before the development project (Cernea 1993, 392). This justification entails an implicit moral responsibility on the part of states and international institutions to ensure the proper compensation of people displaced as a result of development initiatives.

It cannot be said that the Sardar Sarovar Dam is a case wherein all the victims are fully compensated, let alone a case wherein the different social groups are equally sharing in the costs and the benefits of the project. Rather, it is the most vulnerable social groups which are disproportionately carrying the burdens through loss of land and culture. ${ }^{2}$ This is typical of the pattern of environmental displacement in that the particular people deemed "in the way" of national development are often the more vulnerable members of society (Bodley 1990, 137; ICIHI 1987, 53; Penz 1993). However, the fact that such practices are widespread does not make them ethical.

It is also disputable whether or not the development project can even be said to be in the public interest. The project will submerge fertile valley 
land so as to irrigate a larger area of less fertile land elsewhere. It will potentially cause waterlogging and increase soil salinity. It will provide ideal sites for malaria-carrying mosquitoes to breed, causing potential health problems, and submerge a vast area of forest at a time when forest conservation is an acknowledged priority. In addition, it is questionable as to whether the dam can provide the amount of hydroelectricity which proponents suggest ${ }^{3}$ (Baviskar 1995, 200; Savur 1995, 157-61).

The decision to build the Sardar Sarovar Dam is a policy choice-it is possible to decide not to build the dam. Moreover, there are alternatives to building the dam which could conceivably meet the stated development needs better than this project will. Alternatives could include a commitment to support grassroots research into drought-resistant crop species and environmentally-adapted planting methods, as well as supporting research into alternate energy sources. ${ }^{4}$ In fact, there is a case to be made that such investments are the more crucial:

Only 3 percent of India's energy needs are met by electricity, while biomass provides more than 50 per cent. Yet, in the Seventh Plan (1985$1990)$, Rs. 32,000 crores [the crore is an Indian counting unit: it equals 10 million] were allocated for the electricity sector, whereas the development of biomass resources received less than Rs. 2,000 crores. (Baviskar 1995, 27-8)

Electrical energy is used primarily by urban consumers, business, and for agricultural pumping, all at highly subsidized rates. The poor, who depend on biomass for all or most of their energy needs, do not benefit from this subsidy (Baviskar 1995, 28; Savur, 1995, 161-62).

\section{Environmental Displacement}

The displacement as a result of the Sardar Sarovar dam is "environmental" primarily because of one of two reasons. Either the people are being displaced as a result of their restricted access to the environment upon which they depend for their lives and livelihoods, or they are being displaced as a result of the development-induced deterioration of their environment to the point where it can no longer support them. While there are many different groups of people who are both displaced and made vulnerable to displacement as a result of this development project, approximately two-thirds of this number are adivasis-tribal people (Wood 1993, 975).

These displaced people include the following categories:

1) There are the "oustees," i.e. those who are being outright evicted to make way for the dam project. Included in this category are those who are not formally recognized as "Project Affected Persons," since they are being evicted to make way for the canal system, rather than the reservoir (Morse and Berger 1992, xv-xvi, 202-4).

2) There are those who are being displaced as a result of losing a part of the environmental resources upon which they depend for their livelihood. Included in this category are people who are:

i) not actually losing their agricultural land to rising dam waters, but will be losing surrounding lands which they used for other important purposes (ibid., 147);

ii) those who will potentially lose access to environmental resources as a result of catchment area reforestation plans (ibid. 62); and

iii) those who will lose access to environmental resources as a result of the canal creating a physical barrier between themselves and those resources (ibid., 202-4);

3) Finally, there are those whose environment alters to the point of putting their economic livelihoods in jeopardy, including:

i) downstream fishery-dependent people (ibid., 289); and

ii) people who customarily occupy or utilize public land in areas which are targeted for rehabilita- tion sites and who as a result must share surrounding environmental resources with these additional people (ibid., 117-18, 164-66).

\section{Environmental Victimization: Jeopardizing Lives and Livelihoods}

In all of these cases, these are people who fit El-Hinnawi's definition of an environmental refugee since they "have been forced to leave their traditional habitat, temporarily or permanently, because of a marked environmental disruption," caused by the Sardar Sarovar Dam Project, "that jeopardized their existence and/or seriously affected the quality of their life" (El-Hinnawi 1985, 4). Although circumstances varied widely, and thus not all people were affected in the same way or to the same degree, in general, the dam project substantially affected people's economic livelihoods, their culture and their health. As a result, it seems highly unlikely that these environmentally displaced people, even with the aid of the resettlement scheme, will be fully rehabilitated to the standard of living which they were enjoying prior to the development project. This, of course, has ethical implications for this development project, which will be returned to later.

\section{Economic Livelihoods}

The Sardar Sarovar Dam Project affected people's economic security in some very fundamental ways. Many people who were directly displaced as a result of the project received no economic compensation whatsoever. People who were displaced as a result of the canal system, for example, were not considered to be covered under the 1979 Narmada Water Disputes Tribunal ruling concerning "oustees," and thus were not deemed to be entitled to resettlement (Morse and Berger 1992, $x v-x v i)$. Indeed, many received little or no compensation for land lost, and no compensation for other resources, such as fruit trees, destroyed by the Sardar Sarovar project (ibid., 202-3). 
For those who were supposed to be covered under the resettlement and rehabilitation program, there were still many forms of economic victimization. Many, if not most, of the people to be displaced by the development project were tribal "encroachers" on state land because they held no legal title to that land..$^{5}$ Both the state of Maharashtra and the state of Madhya Pradesh chose to interpret the Tribunal ruling regarding "oustees" to mean that only those with formal title to land, and their adult sons, would be given land for land, despite the fact that this would make tribal people, who hold their land by customary usage, landless oustees (ibid., xvii). What must be understood here is that landlessness is an economic disaster for these people's well-being since land is their source of subsistence and knowledge of their local environment is their major skill. As the Narmada Control Authority stated in 1984, "For tribals, there is no rehabilitation more effective than providing land as the source of livelihood" (ibid., xviii).

Even for those who are covered under the resettlement and rehabilitation segment of the development project, their economic security was in many cases jeopardized, even to the point of displacing some family members from one mode of production (that of cultivator) to another, more insecure, mode of production (that of wage earner). In many cases, land which was given was too little or of poorer quality (ibid.,81194).

In addition, the resettlement and rehabilitation policy did not recognize other aspects of economic livelihoods. It did not take into account economic practices such as fishing, pastoralism, and gathering (ibid., 137). Also, the levels of economic productivity which result from local environmental and cultural knowledge has been, for the most part, ignored. Nor did the policy properly take into account the forms of economic security that arise as a result of people's social ties-"[p]eople attribute their economic security to a long established web of human and geographical links within their com- munity" (ibid., 183). These links, of course, would be destroyed where the community was not resettled as a whole.

Perhaps most importantly, however, is the fact that even in the bestcase scenario for resettlement and rehabilitation, the process of displacement precedes that of relocation and rehabilitation (ibid., 88). In other words, there is that period of time wherein people are living a transitory, double existence. There are relocation costs which often have to be paid out before compensation is given. There is also a readjustment period, wherein land must be made ready to cultivate, and the general quirks of a new and different environment adjusted to. Baviskar gives an example of one aspect of the transitionary impact that the Sardar Sarovar Project had on Anjanvara, the village she had lived in just prior to the dam project:

A handpump for the village was sanctioned several years ago, but never installed because the village lies in the submergence zone of the dam. So the last few years and the present have been held captive to an uncertain future. (Baviskar 1995, 201)

All of these transitionary problems negatively impact on economic security. In some cases, they may even prove to cause yet further displacement in the future.

\section{Culture}

Many of these people are also victimized in terms of their cultural well-being. Perhaps the most important means of cultural victimization is the policy stance taken by both the state of Maharashtra and the state of Madhya Pradesh. "Oustees" have the choice of being resettled within their own state, but for many there is very little in the way of a real choice. Most "oustees" in these two states would be considered landless oustees (eligible only for a houselot) because they hold no legal title to land. However, in the state of Gujarat they would be given a minimum of 2 hectares of land. Also, the state of Gujarat has more land available in larger sections, allowing for the potential of at least some families or community groups to resettle together (Morse and Berger 1992, 46). However, in cultural terms, resettling in Gujarat is a loss. For many it would mean moving away from other important family and other social ties. As well, language would become even more of a barrier, since few tribal men and no tribal women know languages other than their own and even then it would be only the official language of the state that they live in (ibid., 134).

Resettlement threatens to culturally victimize people in other ways. These displaced people must adapt their lifestyle in that they are often "moving from relative isolation and independence to a high degree of dependence on public institutions and services to protect against disastrous consequences of the move" (ibid., 109). Also, the caste system and a general lack of social ties has meant that for those resettled, there is almost always little in the way of social bonding with other established communities in the area, leading to social isolation (ibid., 154-55). In all cases where people have resettled, they have expressed a feeling of loss over leaving their home and their gods. Included in this list of losses are even the basics of privacy-many women who were interviewed bemoaned the loss of privacy that the forest provides for bathing and performing their "ablutions" (ibid., 111).

\section{Health}

The physical and psychological wellbeing of all of those who experienced a drop in the standard of their living would potentially be threatened as a result of the resettlement process. As discussed earlier, the loss of one's culture, place, and economic security would certainly affect psychological well-being. And in many cases, even a temporary drop in economic livelihood could result in a loss of access to an adequate and nutritious diet, which would especially affect the health of the very young. "In 1988, the Tata Institute reported unusually high mortality rates among Manibeli oustees, especially children, for the first years 
of relocation" (ibid., 156). Stress and anxiety which would result simply from the anticipation of having to move could quite possibly have both physical and psychological affects.

In addition, many of the resettled areas are lacking in basic infrastructure, such as working water pumps and proper, comfortable housing (ibid., 81-194).

\section{Those Not Counted}

In addition to those who are formally acknowledged as project "oustees," there are many others who are being displaced as a result of both the dam project and the project of resettlement and rehabilitation. ${ }^{6}$ Arguably, the reasons why these people are not acknowledged as being displaced result from the same processes which de-legitimize both the cultural and ecological use patterns of the official "oustees." The main reasons for the difference between "official" and "unofficial" oustees are the legal rights and political visibility of the former and the latters' lack of these.

\section{Patterns of Environmental Displacement}

There are many aspects of this process of environmental displacement which are similar to that of other incidences of environmental displacement throughout the world as well as throughout history. Exploring these "patterns" helps to shed light on why development, which is supposed to be a beneficial process for all, often in actual fact causes both environmental victimization and displacement.

\section{Legacy of Colonialism}

The displacement of tribal people by the Sardar Sarovar Dam has been justified on the grounds that it provides tribal people with an opportunity for development (ibid., 5-6). The reasoning behind this justification parallels that of late-colonial "civilization" missions, which justified cultural and environmental displacement of indigenous peoples on the grounds that it brought the benefits of modern civilization to "backward" cultures. At first, colonialism concentrated on the gains to be made by such means as trading and outright coercive extraction. However, later on, colonialists became more interested, for various reasons, in the well-being of the remaining indigenous peoples within their colonial territories. Forced acculturation provided a means of gaining access to their land and natural resources, as well as a means of forcibly drawing them into the colonial economy - at the bottom rung (Bodley 1990, 7-15).

\section{Modernization as a Continuation of "Civilization"}

With regards to the Sardar Sarovar project, these environmentally displaced people are amongst India's most disadvantaged social groups. Most belong to social groups officially classified as either Scheduled Castes or Scheduled Tribes, meaning that these social groups are officially recognized as being socially disadvantaged as a result of discrimination and thus in need of government assistance for development (Hardgrave and Kochanek 1993, 188-89). While these Scheduled Castes and Tribes are given special government assistance, it is not to allow them a greater degree of autonomy and self-determination. Rather, it is meant to provide a temporary "shelter," so as to allow them some time to adjust to the modern world. This practice is a carry-over from Imperial British protection policies.

The Scheduled Tribes, for the most part, prefer to call themselves adivasi, which is Hindi for "original dwellers." While there is some controversy over how "tribal" these people are as a result of their coexistence with "nontribal" people for centuries, for the most part, those living in the hills have maintained a distinct identity as a result of their relative isolation (Baviskar 1995, 86-88; Morse and Berger 1992, 68).

Others within India tend to view these Scheduled Tribes as being merely "backward Hindus" who are "backward" as a result of being poorly integrated into mainstream Indian so- ciety (Morse and Berger 1992, 65). This is extremely important in terms of justifying displacement since it aids in the legitimization of the imposition of economic development on tribal people as being "for their own good" (Bodley 1990, 117-25). Indeed, Morse and Berger referred to this perception of tribal people, quoting Vidyut Joshi, now of the Gandhi Labour Institute in Ahmedabad, that the displacement to be suffered by tribal people as a result of Sardar Sarovar "was part of the changes that other peoples have welcomed 'in the name of progress, development or modernization'" (Morse and Berger 1992, 65). Vidyut Joshi further stated that:

This being so, why should any one oppose when tribal culture changes? A culture based on [a] lower level of technology and quality of life is bound to give way to a culture with superior technology and higher quality of life. This is what we call "development." What happened to us is bound to happen to them because we both are part of the same society. I have extensively travelled in tribal areas for the last twenty years and I have observed their behaviour. I have formed the opinion that tribals want to change (ibid., 65).

\section{The Sardar Sarovar Dam as Unethical Development}

Development is supposed to be beneficial. It is supposed to be the creation of a better life. Within the context of a nation, the state is supposed to be committed to the development of the people as a whole. It has a responsibility to ensure an equitable distribution of the costs and benefits of development projects, especially when they are state projects. Yet the potential benefits of the creation of the Sardar Sarovar Dam are to accrue to a better-off segment of Indian society-those who can afford electricity ${ }^{7}$ and those who hold land in Gujarat or Rajasthan which would become properly irrigated as a result of the development project. In turn, the costs are largely being born by an already disadvantaged segment of society-Scheduled Castes and Scheduled 
Tribes. Many members of these groups do not have formal title to their lands and therefore little recourse to mainstream legal channels when it comes to compensation. This leaves the vast majority of displaced people with practically no bargaining power over their fate.

Although there are provisions to resettle and rehabilitate at least some of the people who will be displaced as a result of the Sardar Sarovar Dam, resettlement still generally means a drop in the quality of living. (An exception are those resettled in the "model" sites which proponents of the dam project have topping the tour list.) The resettlement and rehabilitation project, which is supposed to be a "development opportunity," is, in actual fact, undermining the economic livelihoods and quality of life of these people. Over the long term, this might even mean further displacement as essential needs are not met. As such, resettlement is not improving the standard of living as defined by the displaced people themselves. In addition, there are all those who, though harmed in various ways by the dam project, are not receiving even the inadequate compensation of rehabilitation, because they hold no formal title to the land or waters that they use for economic livelihood purposes.

\section{Conclusion}

The Sardar Sarovar Dam is a case of a development project which is both directly and indirectly causing a massive amount of environmental displacement. This displacement is not limited to the present. Rather, the effects of both the dam project and its accompanying resettlement and rehabilitation project are setting the stage for further displacement by increasing people's economic vulnerability. Those who must bear the majority of the development costs in this project were neither properly consulted, nor compensated in ways acceptable to them. Moreover, the Sardar Sarovar Dam is development on the backs of the poor, as the people being displaced are amongst India's most vulnerable and disadvan- taged social groups. For these reasons, the Sardar Sarovar Dam project cannot be considered to be ethical development.

\section{Notes}

1. This argument ignores the state's role in contributing to the environmental degradation and deforestation of India's forest lands. (See Amita Baviskar, In the Belly of the River, 1995, 137-49, for a detailed explanation of the state's role). This blamethe-victim approach to the existing environmental degradation allows the state's role in reforestation as a necessary part of the medium- to long-term success of the Narmada Valley Project to remain plausible.

2. Amita Baviskar $(1995,219-22)$ points out that there is another social group, the Patidars in Nimar, which is being displaced. While this somewhat complicates the issue of social justice, I do not think that this completely undermines the thrust of the vulnerability argument. The Patidars are landowners who will receive a much fairer amount of compensation than either the adivasi (i.e., tribal) hill dwellers or the adivasi and other wage labourers. In addition, there is a case to be made that both groups are being victimized by city electricity-users and wealthy Gujarati farmers.

3. In addition, it is questionable that the irrigation component will be entirely successful. Venkata Reddy (1990) has extensively documented the myriad of practical problems which inhibit the success rate of large-scale dams.

4. For suggestions of alternative energy sources, see Manorama Savur (1995).

5. Encroachment is a product of colonial state forestry practices, which redefined property rights. The practice of shifting cultivation, which allowed land to be replenished, was frozen in time to the particular plot that was in use when "legal holdings" were measured. As well, these holdings were smaller than that necessary for ensuring total food requirements, since shifting cultivation was supplemented with secondary forest products (whose use is also now illegal). The soil, which is not suited for sustained use, plus the small total amount of legal holdings, requires that these people make use of supplementary, "illegal" plots (Baviskar 1995, 150-51).

6. Morse and Berger (1992, 117, 164-66) report instances wherein people are resettled on land which had been "encroached" upon by others.
7. This is somewhat modified by the extensive amount of illegal tapping of electricity in India. However, these illegal sources of electricity are by no means secure.

\section{References}

Baviskar, Amita. 1995. In the Belly of the River: Tribal Conflicts over Development in the Narmada Valley. Delhi: Oxford University Press.

Bodley, John H. 1990. Victims of Progress. Mountain View: Mayfield Publishing Co.

Cernea, M. 1993. "Disaster-related Refugee Flows and Development-caused Population Displacement." In Anthropological Approaches to Resettlement: Policy,Practice, and Theory, edited by M. Cernea and S. E. Guggenheim, 376-97. San Francisco: Westview Press.

Doria, Radheshyam. 1990. Environmental Impact of the Narmada Sagar Project. New Delhi: Ashish Publishing House.

El-Hinnawi, E. 1985. Environmental Refugees. Nairobi: United Nations Environment Programme.

Hardgrave, Robert L., and Stanley A. Kochanek. 1993. India: Government and Politics in a Developing Nation. Toronto: Harcourt Brace Jovanovich College Publishers.

Independent Commission on International Humanitarian Issues. 1987. Indigenous Peoples: A Global Quest for Justice. London: Zed Books.

—. 1986. Refugees: The Dynamics of Displacement. London: Zed Books.

Morse, Bradford, and Thomas Berger. 1992. Sardar Sarovar: Report of the Independent Review. Ottawa: Resource Futures International Inc.

Penz, Peter. 1993. "Colonization of Tribal Lands in Bangladesh and Indonesia: State Rationales, Rights to Land, and Environmental Justice." In Asia's Environmental Crisis, edited by Michael C. Howard. Colorado: Westview Press.

Reddy, Venkata. 1990. The Dynamics of Irrigation Water Management. New Delhi: Ashish Publishing House.

Savur, Manorama. 1995. "Let us Not Dam Development." In Contradictions in Indian Society, edited by Manorama Savur and Indira Munshi, 153-74. Jaipur: Rawat Publications.

Wood, John R. 1993. "India's Narmada River Dams:Sardar Sarovar UnderSiege." Asian Survey 33, no. 10 (October): 968-84. ם 